\title{
Self-care in primary care: findings from a longitudinal comparison study
}

\author{
Anne-Marie Bagnall ${ }^{1}$, Jane South ${ }^{2,3}$, Mark J. Forshaw ${ }^{4}$, Christopher Spoor ${ }^{5}$, \\ Paul Marchant ${ }^{6}$, Karl Witty ${ }^{7}$ and Alan K. White ${ }^{8}$ \\ ${ }^{1}$ Senior Research Fellow, Faculty of Health and Social Sciences, Leeds Metropolitan University, Leeds, UK \\ ${ }^{2}$ Director of Centre for Health Promotion Research, Faculty of Health and Social Sciences, Leeds Metropolitan \\ University, Leeds, UK \\ ${ }^{3}$ Professor of Healthy Communities, Faculty of Health and Social Sciences, Leeds Metropolitan University, Leeds, UK \\ ${ }^{4}$ Principal Lecturer in Psychology, Centre for Health Psychology, Faculty of Sciences, Staffordshire University, Stoke- \\ on-Trent, Staffordshire, UK \\ ${ }^{5}$ Principal Lecturer in Health Promotion and Economics, Faculty of Health and Social Sciences, Leeds Metropolitan \\ University, Leeds, UK \\ ${ }^{6}$ Statistician, University Research Office, Leeds Metropolitan University, Headingley Campus, Leeds, UK \\ ${ }^{7}$ Research Officer, Faculty of Health and Social Sciences, Leeds Metropolitan University, Leeds, UK \\ ${ }^{8}$ Professor of Men's Health, Faculty of Health and Social Sciences, Leeds Metropolitan University, Leeds, UK
}

\begin{abstract}
Aim: To examine the effects of self-care training workshops for primary healthcare workers on frequently attending patients. Background: Interventions to promote selfcare in frequent users of primary care services have had mixed results. This paper reports an evaluation of a self-care initiative that aimed to develop a practice-based strategy to support self-care. Methods: A 12-month longitudinal-matched comparison study was carried out in seven intervention and four comparison practices. The intervention was a multidisciplinary training package delivered to Primary Care Trusts (PCTs) and practice staff in three workshops, over a three- to six-month period. Twenty-one managers, health professionals and other staff from participating practices and PCTs and 1454 patients were involved in the study. 'Frequently attending' patients were defined as having visited the practice more than eight times in the previous year, and were identified from practice registers and recruited by letter.

Three sets of data were obtained: psychometric scores and other data from structured questionnaires; routinely collected data on use of healthcare services; and self-care beliefs and behaviour from qualitative interviews. Findings: Study recruitment rate was $20 \%$ and retention rate $75 \%$. Of those recruited $66 \%$ were female and the majority $(94.8 \%)$ were White. There was poor uptake of the training programme within the participating practices, with few changes agreed or implemented. Few healthcare professionals consented to take part in the evaluation. No significant changes were seen in patients' use of health services, psychometric scores or self-care beliefs or behaviour. Conclusion: The initiative did not show any effects during its pilot phase. Uptake and implementation were adversely affected by competing pressures for time and resources in primary care, coupled with a lack of engagement from primary health care professionals.
\end{abstract}

Key words: frequent attenders; general practice; health service use; intervention; primary care; self-care

Received 8 August 2011; revised 14 March 2012; accepted 19 March 2012;

first published online 23 April 2012

Correspondence to: $\mathrm{Dr}$ Anne-Marie Bagnall, $\mathrm{PhD}, \mathrm{BSc}$ (Hons), Faculty of Health and Social Sciences, Leeds Metropolitan University, Woodhouse Lane, Leeds LS2 8NU, UK. Email: a.bagnall@leedsmet.ac.uk

(C) Cambridge University Press 2012 


\section{Introduction}

A substantial proportion of a General Practice's workload can be attributed to a relatively small proportion of the practice population who attend frequently. Definitions of 'frequent' attendance vary from threshold numbers of visits to a fixed proportion of patients with the highest consultation rate (Vedsted and Christensen, 2005). One systematic review reported that most studies used a definition of 9-14 visits per year (Gill and Sharpe, 1999), while a later review found the top $10 \%$ of attenders accounted for $30-50 \%$ of all contacts (Vedsted and Christensen, 2005). In the United Kingdom, analysis of appointment data from nine Sheffield Practices for 1997-1998 found that frequent attenders (attending more than 19 times per year) comprised $1.3 \%$ of the patient population, but generated $8.3 \%$ of consultations (Eve et al., 2000). Other UK studies, one in an isolated rural practice and one in a large teaching practice, found that frequent attenders (attending more than 11 times per year) created five times the consultation workload of a similar group (Heywood et al., 1998; Stewart and O'Dowd, 2002). The larger study (Heywood et al., 1998) reported that $94 \%$ of frequent attenders had a chronic health problem compared with $39 \%$ of non-frequent attenders. Systematic reviews (Gill and Sharpe, 1999; Vedsted and Christensen, 2005) also found that frequent attenders were more likely to have health problems compared with other attenders. Included studies differed with regard to which physical diseases were most prevalent, although respiratory and musculoskeletal disorders were common (Vedsted and Christensen, 2005).

In 1999, the UK Department of Health established the Expert Patients' Task Force (Department of Health, 1999) to design a programme of lay-led self-management strategies, enabling people with chronic illness to 'maintain their health and improve their quality of life'.

The National Health Service (NHS) Plan (Department of Health, 2000) confirmed the commitment to self-care, and further impetus was provided by the Wanless Report (Department of Health, 2002), a key recommendation being the need for a more active 'fully engaged' patient who is involved in all aspects of health care including prevention, treatment and management of illness (Wright, 2002). In the Wanless vision, strategies to prevent illness and treat minor ailments take place at home or otherwise outside the healthcare setting, with support from primary health care professionals (PHCPs). In 2004, the Public Health White Paper, 'Choosing Health' (Department of Health, 2004) emphasised individual responsibility for looking after health, with a more detailed description of the self-care strategy laid out in 'Self-care - a real choice, Selfcare support - a practical option' (Department of Health, 2005b). The importance of increasing self-care, patient-led approaches to care and shared decision-making continue to be emphasised under the new government arrangements outlined in the white papers 'Equity and Excellence' (Department of Health, 2010a) and 'Healthy Lives, Healthy People' (Department of Health, 2010b).

Although people identify self-care information as crucial to boosting their willingness and capacity to self-care (Department of Health, 2005a), studies have shown that simply providing selfcare information does not reduce service use (Vingilis et al., 1998; Heaney et al., 2001; Eijken et al., 2004) and may even increase it (Terry and Pheley, 1993). However, some studies of educational interventions aimed at self-management of illness by frequent attenders and those with longterm conditions have shown small reductions in service use combined with small health gains (Montgomery et al., 1994; Fries and McShane, 1998; Kennedy et al., 2003; Lovell et al., 2003). The main source for self-care information, and the source which people say they prefer, after family and friends, is the general practitioner (GP; Department of Health, 2005a). After knowledge and information, patients regard guidance from professionals as the second most important factor in enabling them to practice self-care, however, they feel that professionals do not encourage them to do so (Department of Health, 2005a). This suggests a need to develop the role of health professionals in actively supporting self-care, and there is some evidence that training in patient-centred communication for enhancing self-management of longterm conditions is welcomed by professionals (Kennedy et al., 2005).

In 2005, the Working in Partnership Programme was established to promote the effective use of health services and to provide evidence-based alternatives to traditional general practice. 
A number of pilot projects were developed to determine how best to support people within their own communities. One of these was Self Care in Primary Care (SCinPC; Working in Partnership Programme, 2006).

SCinPC involved the design of an educational programme for primary healthcare teams. It aimed to actively engage professionals and patients in selfcare. The premise was that, through training, health professionals become more skilled and confident at passing on self-care advice and guidance. Patients in turn would become more knowledgeable, skilled and confident in self-caring and making decisions about their health, which could then reduce consultations with PHCPs. A sister programme (Self Care for People) focused on delivering self-care skills training courses to people in the community (White et al., 2009; South et al., 2010).

An evaluation of SCinPC was undertaken to assess the development and implementation of the initiative and its impact on Primary Care Trusts (PCTs), practices, frequently attending patients and local health economies. This paper reports the main findings of the evaluation.

\section{Methods}

\section{Intervention}

The SCinPC initiative was implemented in four PCTs that agreed to be pilot sites. Its main aims were to develop key self-care support skills for PHCPs, improve the understanding of NHS selfcare policies and facilitate the development of local strategies to support self-care. The SCinPC training package, developed by Staffordshire University, included workshops and tools to help develop a practice-based strategy supporting self-care, and gave practical examples of how self-care could be delivered (Chambers et al., 2006). The training was designed with the intention that practices would take ownership by identifying their needs and priorities, choosing specific topics and learning ways of working that would transfer to other topics in the longer term.

Primary Care practices and PCTs taking part in the initiative received three 3-hour workshops delivered by local facilitators from the PCT or the private sector. The workshops were held over a period of three to six months and all practice staff were encouraged to attend.

\section{Study design}

The evaluation design was quasi-experimental and allowed comparison between practices implementing the intervention and practices with no intervention. Changes in study participants were tracked over 12 months. Seven practice managers volunteered to undertake the intervention in the four pilot PCTs. A further four practices were selected as comparison sites based on geographic and/or demographic similarities: three within the pilot PCTs and one in a separate PCT.

Data were drawn from different methods and data sources, thereby strengthening evidence by triangulation (Green and South, 2006). Three research methods were used:

1) Health service utilisation data were collected on each frequently attending (defined as more than eight visits per year) participating patient.

2) Structured questionnaires were administered to all participating patients, and to healthcare professionals and staff at intervention practices and PCTs, at baseline, six and twelve months.

3) Qualitative, semi-structured interviews were conducted with healthcare professionals and staff at intervention practices and PCTs at around six months, and with a subsample of frequently attending patients from intervention practices at baseline, six and twelve months.

\section{Outcome measures}

A central premise of SCinPC was that an intervention designed to enhance self-care skills in health professionals would result in changing patterns of service use in frequently attending patients. It was hypothesised that participation in the self-care training course would result in improved communication with patients and more appropriate workload management, leading to intermediate outcomes of increased self-care knowledge and skills in healthcare professionals, yielding increased confidence and intention to discuss self-care with patients. This would impact on patients in the longer term, leading to increased knowledge, skills, confidence and intention to self-care.

The primary outcome variable was change in number of general practitioner (GP) consultations among frequently attending patients. Routinely collected data on health service use were obtained 
from participating General Practices. Data were collected for each study participant for the following variables: GP consultations, and consultations with other PHCPs, in person or by telephone.

Structured questionnaires were administered to all patients at baseline, six and twelve months, incorporating items from standardised psychometric scales: anxiety (HADS, Zigmond and Snaith, 1983), perceived stress (Short PSS-4, Cohen and Williamson, 1988), self-esteem (Rosenberg Self-Esteem Scale, Rosenberg M, 1989), recovery locus of control (Recovery Locus of Control Scale, Partridge and Johnston, 1989) and subjective well-being (Subjective Well-being Scale, Diener et al., 1989).

There were also questions on: demographic information; health status; social support; knowledge of minor ailments; self-reported service use; health literacy with regard to service use; and exposure to other self-care initiatives and resources.

Qualitative interviews used a topic guide to elicit information on aspects including self-care beliefs and behaviour, barriers and facilitating factors, changes in service use, access to sources of support and other health and social outcomes.

Interviews with stakeholders, practice staff and professionals were carried out face to face, whereas those with patients were carried out by telephone. All interviews were digitally recorded and transcribed or written in annotated form.

\section{Sample}

The sample was drawn from those people who were identified as having attended the practice more than eight times in the previous year and included men and women aged 16 years and over. People with pregnancy, terminal illness or severe mental illness were excluded. Practice managers were given discretion to make other exclusions for any reason.

A sample size calculation was carried out using the primary outcome of change in GP consultation rate. An estimated mean annual GP visit rate of eight in frequently attending patients, and an effect of $20 \%$ reduction gave a required sample size of 250 participants in each group at the end of the 12-month follow-up period for a statistical power of $90 \%$ and a critical significance level of 0.05 (assuming the effect of clustering to be negligible). Recruitment targets were set at 550 in each group, which included allowance for a $30 \%$ attrition rate at both six- and twelve-month time points.
Recruitment packs containing information about the study, baseline questionnaires and consent forms were sent by post from each practice to all potential participants. In line with the proposal submitted to the research ethics and the PCT Research \& Development committees, all those involved in the study, including stakeholder interviewees, gave their written consent for inclusion.

\section{Analysis}

For routine data on service use, two six-month periods were designated as 'baseline' and 'followup'. The baseline period for each participant referred to the six months prior to the first day of the month in which they joined the study. The follow-up period referred to the same six-month period, one calendar year later, to account for seasonal trends.

Numbers of consultations with GPs and other PHCPs were counted for each participant within the baseline and follow-up periods. For simple exploration the change in number of consultations between the baseline and follow-up six-month period was calculated for each participant. Means and $\sim 95 \%$ confidence intervals for these differences were then calculated by group (intervention versus comparison) and by practice (SPSS 16.0, IBM, Armonk, New York, USA).

A multilevel model was run of the number of consultations per patient (level 1) in the follow-up period, taking into account number of consultations at baseline (adding 0.5 to the log of number of consultations at baseline to avoid problems with zero counts), practice (level 2) and group (intervention or comparison) using negative binomial distribution with a logarithmic link function, second order PQL with no over dispersion applied to count variables (MLWin 2.0, Centre for Multilevel Modelling, University of Bristol, Bristol, UK). A sensitivity analysis was run using the last observation carried forward for participants with missing outcomes on number of consultations.

Total scores on psychometric scales were calculated for each participant, and the mean and standard deviation in intervention and comparison groups at each time point were determined. Questionnaires with partial and non-responses to single or multiple items in the psychometric scales were excluded from the analysis for that scale. Multivariate linear regression analysis was undertaken 
(complete case analysis) with the dependent variables being scores at six and twelve months, and predictor variables being scores at baseline, gender and group (intervention or comparison).

Responses to ordinal scales on knowledge of minor ailments, perceived health status and social support were compared between groups at six and twelve months' follow-up using the $\chi^{2}$ test for independence.

The qualitative data were managed with the NVivo7 software package (QSR International (UK) Limited, Southport, UK) and analysed by two researchers who inductively created a coding framework that was used to organise the data into major thematic categories and subcategories using a refined framework (Mason, 1996; Pope et al., 2000).

\section{Results}

\section{Key stakeholder interviews}

All the self-care leads from intervention PCTs, trainers and managers from intervention practices were invited to take part in interviews. Other PCT staff included in the sample were recommended by PCT leads, either because they were involved in similar work or had been instrumental in competing for the SCinPC initiative. In total, 25 stakeholders were invited to take part in interviews, and 21 interviews were conducted with four PCT leads, five practice managers, three trainers/facilitators and five other PCT staff six to twelve months after the initiative began. Many of those involved had previously worked on long-term conditions, patient/public involvement and/or health inequalities. There was a limited response from health professionals to requests for interviews.

Interviews revealed that stakeholders felt the initiative complemented the NHS drive to improve the population's health through greater self-care support, but saw it as a shift from the way the NHS normally operated. Additional pressures on PCTs and practices due to the concurrent reorganisation of primary care were reported. It was suggested that, for the initiative to work, the public and all levels of the health service needed to be informed of the changing culture and their place within it.

PCT staff were positive about the initiative, but felt that 12 months was possibly too short a time period to see its effects.
Practices found it harder to assimilate the necessary culture change due to three main factors as outlined below.

1. Problems in running the training packages as envisaged due to the level of commitment required from practice staff and mismatched expectations of the course content:

Facilitators expressed difficulties gaining access to practices and arranging sessions. They found they had to shorten the programme and make it more appealing to practice staff. The feedback from the practices was that they expected to be told 'how to' implement self-care, whereas what they received were discussions on the nature of self-care. The package did in fact contain a number of 'how to' tools but interviewees did not mention these.

Most of the barriers with delivering the training have been GPs saying they are too busy or don't have the resources. Just getting into a GP Practice is difficult in terms of the bureaucracy.

PCT-based stakeholder ... another practice that said we can't do it in that [3 sessions of 3 hours] but you can tag on to the end of our practice meeting. They gave us $20 \mathrm{~min}$ and that was fairly disastrous. What they didn't understand was that this was about them being given a framework within which they could consider how to increase the amount of work that they did in a self care type of way... it wasn't about going in and delivering a training session that says this is how you do self care.

PCT-based stakeholder

2. Perceived resistance among health professionals, particularly GPs, to change current ways of working:

Stakeholders reported that many of the frequent attenders said that they kept returning because the doctor asked to see them. There was recognition that, for some GPs, patients with minor problems create a welcome relief within a busy caseload.

The patients kept saying 'I don't want to keep coming in it's your doctor that keeps asking 
me to come in'. You need to tell your doctor if you don't want me to come in.

Practice-based stakeholder

Some of the GPs that we've worked with have said themselves that they believe that they are responsible in part for not encouraging patients to self care, because obviously they're people who have come into a service and they want to be needed.... to actually hand control over to patients and lots of information to patients can potentially threaten their own value.

PCT-based stakeholder

A new skill set was thought to be needed within consultations to direct patients towards self-care. Respondents felt that GPs needed to be more aware of health, rather than treating illness, as a goal.

3. Perceived resistance among patients to change current ways of consulting:

Stakeholders were concerned that many patients expected to have direct access to their GP.

There's still a cultural thing... people believe that seeing the doctor is the thing they want. When you offer them something else, whether to see the nurse or pharmacist or self care, people aren't nasty but they do believe it's a second best.

Practice-based stakeholder

It appeared that most activity within practices was focused on setting up triage systems for managing workload.

\section{Patients}

The response rate to the postal questionnaire was $20 \% .1454$ patients took part in the study (see Table 1). Of these, $66 \%$ were female and $95 \%$ were White. A higher proportion of people in the comparison than the intervention group reported having no qualifications ( $36 \%$ versus $24 \%$ ), and a higher proportion in the intervention than the comparison group reported having a degree or equivalent $(26 \%$ versus $15 \%)$. Higher levels of social support and better perceived health were also reported in the intervention group.

1041 questionnaires were returned at six months and 1018 at 12 months, giving a retention rate of $70 \%$ from baseline.

Primary Health Care Research \& Development 2013; 14: 29-39
Table 1 Participant (patient) characteristics at baseline

\begin{tabular}{lccr}
\hline $\begin{array}{l}\text { Category of } \\
\text { participants }\end{array}$ & \multicolumn{1}{l}{$\begin{array}{l}\text { Intervention } \\
n(\%)\end{array}$} & $\begin{array}{l}\text { Comparison } \\
n(\%)\end{array}$ & $\begin{array}{l}\text { Total } \\
n(\%)\end{array}$ \\
\hline Total & 746 & 708 & 1454 \\
Male & $266(36)$ & $225(32)$ & $491(34)$ \\
Female & $472(64)$ & $474(68)$ & $946(66)$ \\
White & $688(94)$ & $672(96)$ & $1360(95)$ \\
Black & $29(4.0)$ & $25(3.6)$ & $54(3.8)$ \\
Asian & $9(1.0)$ & $1(0.1)$ & $9(0.6)$ \\
No qualifications & $166(24)$ & $221(36)$ & $387(30)$ \\
Degree or equivalent & $177(26)$ & $92(15)$ & $269(21)$ \\
Live with family & $537(73)$ & $521(75)$ & $1058(74)$ \\
Live alone & $183(25)$ & $153(22)$ & $336(23)$ \\
Health conditions & $626(85)$ & $579(83)$ & $1205(84)$ \\
\hline
\end{tabular}

Table 2 Mean (SD) consultations over baseline and follow-up six-month periods

\begin{tabular}{lll}
\hline Consultations & $\begin{array}{l}\text { Intervention } \\
n=704\end{array}$ & $\begin{array}{l}\text { Comparison } \\
n=650\end{array}$ \\
\hline GP & & \\
$\quad$ Baseline & $5.00(5.42)$ & $7.09(5.32)$ \\
$\quad$ Follow-up & $4.33(5.85)$ & $6.07(5.32)$ \\
Other PHCPs & $1.48(1.99)$ & $1.86(2.40)$ \\
$\quad$ Baseline & $1.60(2.89)$ & $1.61(2.77)$ \\
Follow-up & & \\
\hline
\end{tabular}

$\mathrm{PHCP}=$ primary health care professionals.

$n=$ number with data for both baseline and follow-up periods.

Eighty patients were interviewed at baseline. At six months, only those participants who had been to the GP practice in the previous six months (52 patients) were re-interviewed. At 12 months, 50 of the original 80 patients were interviewed.

\section{Routine data}

Mean number of contacts with services during baseline and follow-up periods in intervention and comparison groups with standard deviations are presented in Table 2.

The multilevel model found that the intervention did not make a detectable difference to the number of consultations with GPs or other PHCPs in the follow-up period, taking into account the number of baseline consultations and practice. The confidence interval for the multiplicative factor by which the number of GP consultations in a six-month period increased afterwards being in an intervention practice rather than a comparison group practice 
Table 3 Group scores at 0, 6 and 12 months for psychometric and other scales

\begin{tabular}{|c|c|c|c|}
\hline Scale & Intervention & Comparison & $P$-values \\
\hline \multicolumn{4}{|l|}{ Anxiety } \\
\hline Baseline & $6.47(4.31) 723$ & $7.44(4.62) 679$ & 0.00006 \\
\hline Six months & $6.16(4.11) 516$ & $7.12(4.37) 503$ & 0.00003 \\
\hline 12 months & $6.08(4.16) 510$ & $6.89(4.24) 454$ & 0.003 \\
\hline \multicolumn{4}{|l|}{ Stress } \\
\hline Baseline & $5.22(3.48) 733$ & $6.01(3.44) 687$ & 0.00002 \\
\hline Six months & 5.05 (3.33) 526 & 5.77 (3.27) 501 & 0.0005 \\
\hline 12 months & 4.84 (3.25) 521 & $5.64(3.10) 461$ & 0.0001 \\
\hline \multicolumn{4}{|l|}{ Self-esteem } \\
\hline Baseline & $19.42(4.97) 711$ & $20.49(5.14) 669$ & 0.00009 \\
\hline Six months & $19.26(5.00) 517$ & $20.40(4.88) 494$ & 0.0003 \\
\hline 12 months & $18.74(4.97) 481$ & $20.13(4.80) 432$ & 0.00002 \\
\hline \multicolumn{4}{|l|}{ Well-being } \\
\hline Baseline & $23.61(6.96) 721$ & $21.83(7.03) 693$ & 0.00002 \\
\hline Six months & $23.96(6.98) 531$ & $22.05(7.03) 510$ & 0.00001 \\
\hline 12 months & $24.02(7.12) 525$ & $22.73(6.79) 471$ & 0.004 \\
\hline \multicolumn{4}{|l|}{ Locus of control } \\
\hline Baseline & $34.11(4.24) 705$ & $33.34(4.32) 676$ & 0.001 \\
\hline Six months & 34.28 (3.96) 515 & $33.56(4.26) 497$ & 0.006 \\
\hline 12 months & $34.46(4.25) 512$ & $33.56(4.51) 458$ & 0.002 \\
\hline \multicolumn{4}{|l|}{ Health literacy } \\
\hline Baseline & $11.13(1.90) 740$ & $10.95(2.05) 697$ & 0.087 \\
\hline Six months & $11.33(1.82) 532$ & $11.06(1.90) 513$ & 0.022 \\
\hline 12 months & $11.42(1.92) 526$ & 11.07 (1.93) 470 & 0.004 \\
\hline
\end{tabular}

All values reported as mean (SD) $n$. Groups compared using Student's $t$ test.

ranged from a reduction in visits of around $40 \%$ of what they were at baseline $(0.4026)$, to an increase in visits by around one-third (1.347; average effect $=$ a reduction of around three quarters of that at baseline (0.736)) The confidence interval for the multiplicative factor by which the number of consultations with other PHCPs was 0.892 to 1.439 with the average of 1.133. Neither effect was statistically significant, as the confidence intervals included one.

\section{Questionnaire data}

Table 3 presents mean scores with standard deviations in the intervention and comparison groups at baseline and follow-up for validated psychometric scales and for a health literacy scale developed by the evaluation team and relating to decision-making around service use. Groups were compared initially using Student's $t$ test.

Baseline measurements indicated statistically significantly lower anxiety and stress scores in the intervention than the comparison group, combined with higher self-esteem and well-being, and a greater internal locus of control. Scores on all scales improved in both groups over time, but the difference between groups was maintained throughout the follow-up period, indicating that there was no differential effect of the intervention. Health literacy scores, which showed no statistically significant difference between groups at baseline, also improved in both groups over time, but in this case the scores in the intervention group were statistically significantly higher than in the comparison group at six and twelve months follow-up.

The results of the multivariate linear regression model showed that there were no statistically significant differences in the six- or twelve-month change scores between intervention and comparison groups on any of the psychometric scales.

Analysis of ordinal data revealed no differential effect at follow-up of being in the intervention group on change in perceived health status, levels of social support, knowledge of minor ailments or intended future use of health services.

\section{Interview data}

From the interview data, it was apparent that patients were confident in their ability to self-care, although there was wide variation in definitions and understanding of the concept of self-care and what it involved.

Primary Health Care Research \& Development 2013; 14: 29-39 
When interviewees had health problems, their choice of support was strongly related to the perceived level of seriousness or concern attached to ailments.

My GP would be the first port of call if I felt there was something that warranted proper medical intervention. I would only use these other things if I felt it was something fairly minor that I could manage myself, you know with a bit of advice.

Female aged 58

Interviewees were concerned about continuity of care and accessibility of primary care services.

Those who were interviewed were largely unaware of any changes within practices with regard to self-care support, although the appointment system was commonly reported to have changed, specifically with the introduction of triage. Most patients who were interviewed had not been, or were unaware of being, given self-care advice by anyone at the practice.

\section{Discussion}

Despite strong stakeholder support for the SCinPC initiative in pilot PCTs and practices, and agreement from participating practice managers to undertake the initiative, it was not successful. Patient-level outcomes showed no effect on consulting patterns or any other outcomes including patients' awareness of self-care. A number of factors could account for this, the most striking being poor implementation at practice level.

The Quality Outcomes Framework and PracticeBased Commissioning were both introduced in UK primary care during the SCinPC pilot phase. Both had a direct impact on practice workload, and, unlike the SCinPC initiative, involved incentives for practices. These changes affected both intervention and comparison practices. In addition, a large-scale reorganisation of PCTs also took place within the study timescale.

The initiative was based on a hypothesis that the training would lead to increased support for self-care at both practice and individual consultation level (Figure 1). What seems to have happened is that in some practices, support was increased at practice level without a corresponding increase in individual support. This could be

Primary Health Care Research \& Development 2013; 14: 29-39

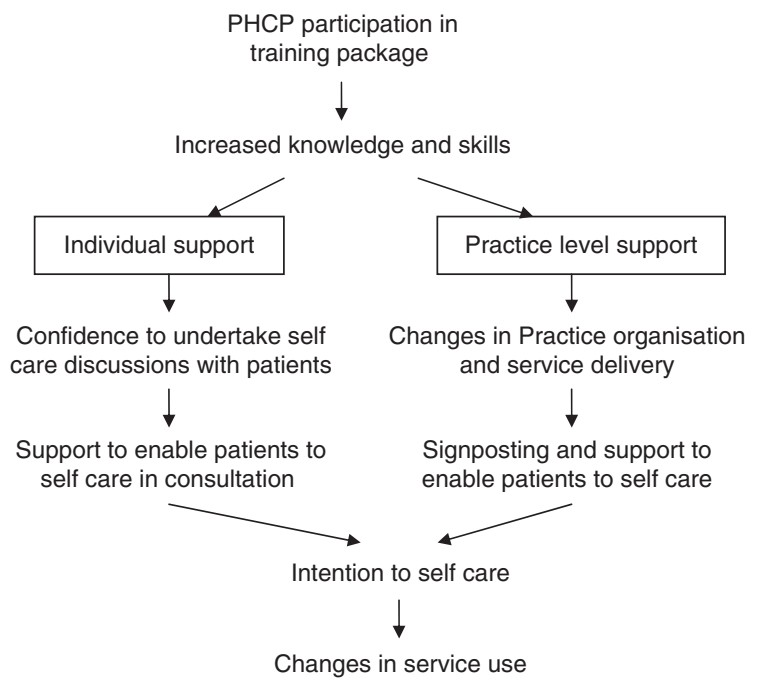

Figure 1 Proposed effects of SCinPC initiative. SCinPC = Self Care in Primary Care; $\mathrm{PHCP}=$ primary health care professional.

due to a number of factors, including constraints on professionals' time, and a belief that the current consulting style did not need to be changed (Kennedy et al., 2005).

Where changes occurred, these involved workload management tools, specifically receptionist- or nurse-led triage. Receptionist-led triage was not popular with patients, who did not want to share details of their illness, or with receptionists, who did not feel confident to undertake triage and feared adverse medical or legal consequences if expected to advise on caring for minor ailments.

Another key issue was timescale: the intervention was delivered over a six-week period, and followed up for 12 months. Most stakeholders interviewed felt that 'embedding' self-care in primary care services would require a cultural shift within the NHS and individual consultations, which would take more time and resources to support and realise.

Practice-based self-care interventions have been shown to work in other contexts (McLean and Pietroni, 1990; Christensen et al., 2004; Bellon et al., 2008). Systematic reviews of self-management programmes for long-term conditions have also indicated that these can be successful (Norris et al., 2001; Chodosh et al., 2005).

In line with a recent systematic review (Vedsted and Christensen, 2005), many of those taking part 
in the SCinPC study reported that they had health conditions. The national evaluation of the Expert Patient Programme (NPCRDC National Evaluation Team, 2006) found that, in people with long-term conditions, attending a short course on self-care skills had no impact on health service use, despite moderate gains in self-efficacy and small gains in energy, quality of life, psychological well-being and partnerships with doctors.

Previous evaluative work on implementing selfcare interventions in general practice (Department of Health, 2006; NPCRDC National Evaluation Team, 2006; Greaves and Campbell, 2007) highlighted some major barriers. Among these were:

- A lack of organisational approaches to providing self-care.

- Limited engagement from healthcare professionals.

- A paucity of training for staff on self-care skills.

- Lack of confidence of healthcare professionals in passing responsibility to patients.

Previous research on interventions for changing professional practice (NHS Centre for Reviews and Dissemination, 1999), although acknowledging that there was no universally effective intervention, recommended a systemic approach to developing appropriate implementation strategies involving all groups potentially affected by the proposed change. This would include assessing professionals' preparedness to change and identifying barriers and enabling factors to change. They concluded that successful strategies were likely to be broad-based, multifaceted and have significant costs attached to them.

Even without the above implementation barriers, the intervention's effectiveness may have been limited by the nature of the target population. There may be many reasons for frequent attendance, with patients' personal beliefs about the control of their health directly impacting on the likely success of using self-care approaches (McLean and Pietroni, 1990). Previous research on frequent attendance in primary care found no effective interventions for reducing service use or improving morbidity or quality of life (Woolacott et al., 2006; Smits et al., 2008), and previous research on self-care in primary care (NPCRDC National Evaluation Team, 2006) highlighted individuals' established consulting routines as a barrier to change.

\section{Methodological limitations}

With a recruitment rate of only $20 \%$ of those approached, it is likely that people taking part in the research did not represent the entire population of frequent attenders in primary care; therefore the findings may be of limited generalisability. There were baseline demographic and psychometric differences between participants from intervention and comparison practices; reasons for these differences are unclear, but could be due to differences between practices which chose to receive the intervention and those which did not.

Recruitment of PHCPs was problematic, and perhaps to be expected in the light of previous research findings. The qualitative interviews in practices comprised a low proportion of GPs and a higher proportion of reception staff. This could reflect the reported difficulties in getting GPs to engage with the initiative, or a more general reluctance of GPs to take part in research, which is well documented (Borgiel et al., 1989; Silagy and Carson, 1989; Bell-Syer and Moffett, 2000; Askew et al., 2002; Williamson et al., 2007). It could, alternatively, be seen as being appropriate to the way the initiative was implemented, as receptionist triage was consistently adopted within the practices, while changes involving GPs were rather less prominent.

It is unclear how much of an additional intervention' was provided by the questionnaires and the telephone interviews for the study participants. Findings from the 12-month patient interviews indicated that being in the study may have had a positive effect on some people.

The majority of questionnaires were fully completed which indicates they were understood and meaningful to participants. Language and literacy support services offered by the University, including interviewer administered questionnaires and language support, were not taken up. The crosscultural reliability of the questionnaire may be an issue, as for any survey work (Bhopal et al., 2004). Although every effort was made to include all groups in the research, for a complete picture of the intervention's impact on frequent attenders, alternative research methods that involve less individual commitment might allow inclusion of more people with low literacy or non-english speakers.

Data for GP and PHCP attendance showed substantial variation between practices, which could indicate differences in the way appointments were coded, or different consulting patterns. The 
statistical analysis adjusted for this to some extent by keeping participants linked to their practices. As there were relatively few practices and they varied in how the intervention was applied, we cannot be sure how much of any effect was due to the intervention and how much to the practice, and variation between practices cannot be well determined.

\section{Conclusions}

Previous studies and systematic reviews have shown mixed results regarding the effectiveness of self-care interventions in primary care. This evaluation adds to that body of work: although no changes in service use were seen, problems with implementation mean the initiative's potential effectiveness (if fully implemented) is unclear. Findings suggest that a successful intervention requires systemic changes in practice organisation and patient and professional education, however, further research into these and other potential barriers to change is justified given the ambiguity in the published literature.

\section{Acknowledgements}

This study was funded by the NHS Working in Partnership Programme. Special thanks are due to Katherine Jackson, Frances Darby and Nicola Farrelly for assistance with data collection and analysis. Statistical support for routinely collected service use data was provided by Paul Marchant; statistical support for psychometric and other scores was provided by Mark Forshaw. Ethical approval was granted by the Leeds West NHS Ethics Committee. The full report (White et al., 2009b) is available at http://www.leedsmet.ac.uk/ health/selfcareproject/report_scip.htm.

\section{References}

Askew, D., Clavarino, A., Glasziou, P. and Del Mar, C. 2002: General practice research: attitudes and involvement of Queensland general practitioners. Medical Journal of Australia 177, 74-77.

Bellon, J.A., Rodriguez-Bayon, A., Luna, J.D. and TorresGonzalez, F. 2008: Successful GP intervention with frequent attenders in primary care: randomised controlled trial. British Journal of General Practice 58, 324-30.

Bell-Syer, S. and Moffett, J. 2000: Recruiting patients to randomized trials in primary care: principles and case study. Family Practice 17, 187-91.

Primary Health Care Research \& Development 2013; 14: 29-39
Bhopal, R., Vettini, A., Hunt, S., Wiebe, S., Hanna, L. and Amos, A. 2004: Review of prevalence data in, and evaluation of, methods for cross cultural adaptation of, UK surveys on tobacco and alcohol in ethnic minority groups. British Medical Journal 328, 76-80.

Borgiel, A., Dunn, E., Lamont, C., Macdonald, P., Evensen, M., Bass, M., Spasoff, R. and Williams, J. 1989: Recruiting family physicians as participants in research. Family Practice 6, 168-72.

Chambers, R., Wakley, G. and Blenkinsopp, A. 2006: Supporting self care in primary care. Oxford: Radcliffe Publishing Ltd.

Chodosh, J., Morton, S., Mojica, W., Maglione, M., Suttorp, M.J., Hilton, L., Rhodes, S. and Shekelle, P. 2005: Metaanalysis: chronic disease self-management programs for older adults. Annals of Intern Medicine 143, 427-38.

Christensen, M.B., Christensen, B., Mortensen, J.T. and Olesen, F. 2004: Intervention among frequent attenders of the out-ofhours service: a stratified cluster randomized controlled trial. Scandinavian Journal of Primary Health Care 22, 180-86.

Cohen, S. and Williamson, G. 1988: Perceived stress in a probability sample of the United States. In Spacapan, A., Oskamp, A., editors, The social psychology of health. California: SAGE.

Department of Health. 1999: Saving lives: our healthier nation. London: Department of Health Publications.

Department of Health. 2000: The NHS plan: a plan for investment, a plan for reform. London: Department of Health Publications.

Department of Health. 2002: Securing our future health: taking a long term view - The Wanless Report. London: Department of Health Publications.

Department of Health. 2004: Choosing health, making health choices easier. London: Department of Health Publications.

Department of Health. 2005a: Public attitudes to self care baseline survey, february 2005. London: Department of Health Publications.

Department of Health. 2005b: Self care - a real choice, self care support - a practical option. London: Department of Health Publications.

Department of Health. 2006: Support for self care in general practice and urgent care settings a baseline study. Leeds: Strategy Directorate, Department of Health.

Department of Health. 2010a: Equity and excellence: liberating the NHS. London: Department of Health Publications.

Department of Health. 2010b: Healthy lives, healthy people: our strategy for public health in England. London: Department of Health Publications.

Diener, E., Emmons, R.A., Larson, R. and Griffin, S. 1989: The satisfaction with life scale. Journal of Personality Assessment 49, 71-76.

Eijken, M.V., Wensing, M., Konink, M.D., Vernooy, M., Zielhuis, G., Lagro, T. et al. 2004: Health education on selfmanagement and seeking health care in older adults: a randomised trial. Patient Education and Counseling 55, 48-54.

Eve, R., Hodgkin, P. and Waller, J. 2000: Frequent attenders: who are they? Sheffield: Centre for Innovation in Primary Care. 
Fries, J.F. and McShane, D. 1998: Reducing need and demand for medical services in high-risk persons. A health education approach. Western Journal of Medicine 169, 201-207.

Gill, D. and Sharpe, M. 1999: Frequent consulters in general practice: a systematic review of studies of prevalence, associations and outcome. Journal of Psychosomatic Research 47, 115-30.

Greaves, C.J. and Campbell, J.L. 2007: Supporting self-care in general practice. British Journal of General Practice 57, 814-21.

Green, J. and South, J. 2006: Evaluation. Maidenhead: Open University Press.

Heaney, D., Wyke, S., Wilson, P., Elton, R., Rutledge, P., Sommerville, A. and Wilkie, T. 2001: Assessment of impact of information booklets on use of healthcare services: randomised controlled trial commentary: what's wrong with opting out? Commentary: public opinion may force researchers to seek "opt in" consent for all. British Medical Journal 322, 1218-21.

Heywood, P., Blackie, G., Cameron, I. and Dowell, A. 1998: An assessment of the attributes of frequent attenders to general practice. Family Practice 15, 198-204.

Kennedy, A., Nelson, E., Reeves, D., Richardson, G., Roberts, C., Robinson, A., Rogers, A., Sculpher, M. and Thompson, D. 2003: A randomised controlled trial to assess the impact of a package comprising a patient-orientated, evidence-based selfhelp guidebook and patient-centred consultations on disease management and satisfaction in inflammatory bowel disease. Southampton: Health Technology Assessment 7, number 28.

Kennedy, A., Gask, L. and Rogers, A. 2005: Training professionals to engage with and promote self-management. Health Education Research 20, 567-78.

Lovell, K., Richards, D.A. and Bower, P. 2003: Improving access to primary mental health care: uncontrolled evaluation of a pilot self-help clinic. British Journal of General Practice 53, 133-35.

Mason, J. 1996: Qualitative researching. London: SAGE Publications Ltd.

Mclean, J. and Pietroni, P. 1990: Self care - who does best? Social Science \& Medicine 30, 591-96.

Montgomery, E.B., Liebermann, A., Singh, G. and Fries, J.F. 1994: Patient education and health promotion can be effective in Parkinson's disease: a randomised controlled trial. American Journal of Medicine 97, 429-35.

Norris, S., Engelgau, M. and Narayan, K. 2001: Effectiveness of self-management training in type 2 diabetes: a systematic review of randomized controlled trials. Diabetes Care 24, 561-87.

NHS Centre for Reviews and Dissemination 1999: Getting evidence into practice. Effective Health Care Bulletin, Volume 5. York: University of York.

NPCRDC National Evaluation Team 2006: Final report: the national evaluation of the pilot phase of the expert patient programme. Manchester: National Primary Care Research and Development Centre, University of Manchester.

Partridge, C. and Johnston, M. 1989: Perceived control of recovery from physical disability: measurement and prediction. British Journal of Psychiatry 28, 53-59.
Pope, C., Ziebland, S. and Mays, N. 2000: Qualitative research in health care. Analysing qualitative data. British Medical Journal 320, 114-16.

Rosenberg, M. 1989: Society and the adolescent self-image. Middletown CT: Wesleyan University Press.

Silagy, C. and Carson, N. 1989: Factors affecting the level of interest and activity in primary care research among general practitioners. Family Practice 6, 173-76.

Smits, F.T., Wittkampf, K.A., Schene, A.H., Bindels, P.J. and Van Weert, H.C. 2008: Interventions on frequent attenders in primary care: a systematic literature review. Scandinavian Journal of Primary Health Care 26, 111-16.

South, J., Darby, F., Bagnall, A-M. and White, A. 2010: Implementing a community-based self care training initiative: a process evaluation. Health and Social Care in the Community 18, 662-70.

Stewart, P. and O'Dowd, T. 2002: Clinically inexplicable frequent attenders in general practice. British Journal of General Practice 52, 1000-1001.

Terry, P.E. and Pheley, A. 1993: The effect of self-care brochures on use of medical services. Journal of Occupational Medicine $35,422-26$.

Vedsted, P. and Christensen, M.B. 2005: Frequent attenders in general practice care: a literature review with special reference to methodological considerations. Public Health 119, 118-37.

Vingilis, E., Brown, U., Koeppen, R., Hennen, B., Bass, M., Peyton, K., Downe, J. and Stewart, M. 1998: Evaluation of a cold/flu self-care public education campaign. Health Education Research 13, 33-46.

White, A., South, J., Bagnall, A.-M., Forshaw, M., Spoor, C., Marchant, P., Jackson, K., Witty, K. and Rooke, S. 2009a: An evaluation of the working in partnership programme self care for people initiative. Leeds Metropolitan University, Leeds, UK. Retrieved from http://www.leedsmet.ac.uk/ health/selfcareproject/report_scip.htm

White, A., Bagnall, A.M., South, J., Forshaw, M., Spoor, C., Witty, K. and Rooke, S. 2009b: An evaluation of the Working in Partnership Programme Self Care in Primary Care Initiative. Leeds Metropolitan University, Leeds, UK. Retrieved from http://www.leedsmet.ac.uk/hss/docs/Final_Report_SCinPC.pdf

Williamson, M., Pirkis, J., Pfaff, J., Tyson, O., Sim, M., Kerse, N., Lautenschlager, N., Stocks, N. and Almeida, O. 2007: Recruiting and retaining GPs and patients in intervention studies: the DEPS-GP project as a case study. $B M C$ Medical Research Methodology 7, 42.

Woolacott, N., Orton, L., Beynon, S., Myers, L., and Forbes, C. 2006. Systematic review of the clinical effectiveness of self care support networks in health and social care: CRD Report 34. CRD Reports. York: Centre for Reviews and Dissemination, University of York.

Working In Partnership Programme. 2006: WiPP self care skills training course: participants handbook. London: Working in Partnership Programme.

Wright, K. 2002: NHS funding and reform: the Wanless report, research paper. London: House of Commons Library.

Zigmond, A. and Snaith, R. 1983: The HAD scale. Acta Psychiatrica Scandinavia 67, 361-70.

Primary Health Care Research \& Development 2013; 14: 29-39 